\title{
Using Spotlight Effect to Curb Counterfeit Consumption - An Experimental Investigation
}

\section{INTRODUCTION}

Counterfeiting is a major problem facing brand managers around the world, and it costs the global economy about US\$750 billion annually (d'Astous and Gargouri, 2001; Staake et al., 2009). It is further estimated that the total annual economic value of counterfeit and pirated products will be as much as US $\$ 1,770$ billion by 2015 (BASCAP, 2011). Counterfeit products may constitute up to $20 \%$ of the domestic sales in countries such as China where this problem is particularly severe (Swike et al., 2008). There is a growing consensus about the role of social motives as important drivers of deliberate counterfeit consumption, especially for publicly consumed products. For example, consumers seem to prefer a counterfeit when the original brand allows them to fit into important social situations or to behave in ways appropriate to reference groups (Wilcox et al., 2009). Consumers may also purchase counterfeits to create a socially desirable identity (Schembri et al., 2010) or to gain social approval (Bloch et al., 1993; Cheung and Prendergast, 2006; Turunen and Laaksonen, 2011).

Most consumers buy counterfeit products to reap the benefits of a brand's prestigious image without paying the high price for its genuine version. However, using counterfeit luxury products can be a risky venture because users may have to face negative social consequences if their usage is detected. In fact, previous studies show that social embarrassment (Penz and Stöttinger, 2005), possible loss of respect from important others (Tan, 2002), and negative impression made on peers (Bian and Moutinho, 2009) are all negatively related to attitudes toward and intention to purchase counterfeit products. However, despite growing evidence that the probability of being detected by their significant others is an important factor for consumers 
to consider when making decisions on counterfeit consumption, there is hardly any research on how they estimate this probability and how this probability estimate may affect their counterfeit consumption behaviour. This paper addresses this important research gap.

First, building upon previous studies on likelihood prediction for negative events (e.g., Harris and Corner, 2011; Harris et al., 2009; Weber, 1994; Weber and Hilton, 1990), we argue that consumers may be prone to a pessimism bias when they generate probability estimates; such that, the more severe the outcome of being detected; the higher the likelihood consumers may overestimate the probability of being detected. Second, this pessimism bias is attributable to a spotlight effect, which refers to the tendency of people to believe that their actions, appearance, and internal states are more likely to be noticed by others than is actually the case (e.g., Gilovich et al., 2000; Lacanilao et al., 2011; Russell and Russell, 2010; Savitsky et al., 2001).

A counterfeit user who perceives the outcome as more severe tend to perceive that observers will pay more attention to the counterfeit product s/he uses than is actually the case; consequently, this perceived attention leads to a higher probability estimate. Moreover, consistent with the predictions from the spotlight effect literature, the effect of outcome severity on probability estimate is shown to be an egocentric bias because this effect is mitigated when the counterfeit user is another person instead of oneself. Finally, counterfeit purchase and usage intentions are both negatively related to the probability of being detected as using a counterfeit.

Overall, this paper draws upon the spotlight effect to explain the estimation of the probability of being detected as using a counterfeit, which is an important process in counterfeit consumption and also contributes to the literature by identifying outcome severity as an antecedent to the spotlight effect. To summarise, we address three specific research questions. First, do perceived social consequences influence the probability estimate of being detected? 
Second, if the answer to the first question is yes, what is the mechanism underlying this influence? Third, how does the probability estimate affect counterfeit consumption behaviour?

We used three experimental studies to test all our hypotheses. Study 1 tested the effect of outcome severity on probability estimate by measuring individual differences in outcome severity. Study 2 manipulated outcome severity and tested the mediating role of perceived attention. Study 3 explored the egocentric nature of the severity effect and showed that the moderating role of the target user was mediated by perceived attention. All the three studies used scenario-based experiments, in order to avoid ethical concerns related to asking participants to actually use counterfeit products and to control for all possible confounding factors.

All the three studies were conducted in Hong Kong, a special administrative region of China because past research shows China to be a major producer as well as market of counterfeit products (Cheung and Prendergast, 2006; Sharma and Chan, 2011). Moreover, counterfeit goods are widely available in Hong Kong and both local residents and tourists buy these products (Cheung and Prendergast, 2006; Harvey and Walls, 2003). Therefore, Hong Kong presents a highly relevant socio-economic environment for the study of counterfeit consumption.

\section{CONCEPTUAL FRAMEWORK AND HYPOTHESES}

\section{Factors Influencing Counterfeit Consumption}

Grossman and Shapiro (1988) classified counterfeit purchase into two types, deceptive and non-deceptive. Deceptive counterfeit purchase refers to situations where consumers are not aware that the product they buy is a counterfeit. Non-deceptive counterfeit purchase, which is the focus of this research, involves situations where consumers knowingly purchase counterfeits. 
Non-deceptive counterfeit purchasers can often distinguish counterfeits from genuine brands on the basis of their differences in price, distribution channels, and product quality.

Several researchers have tried to identify the factors that could explain why consumers knowingly purchase counterfeit products (see Eisend and Schuchert-Güler, 2006, for a review). For instance, demographic characteristics (e.g., age, income, education) do not show a consistent relationship with purchase intention (Bian and Moutinho, 2009, 2011; Bloch et al., 1993; Penz and Stöttinger, 2005). Other factors include psychographic factors such as materialism, risktaking, self-identity, perceived behavioural control (Penz and Stöttinger, 2005; Trinh and Phau, 2012; Wee, et al., 1995), cultural norms (Zimmerman, 2013) and experience with counterfeits (Yoo and Lee, 2009). Brand-related factors, such as brand image and brand personality, also impact counterfeit purchase and consumption (Bian and Moutinho, 2009, 2011).

Of particular relevance to this research are the social motives that underlie counterfeit consumption. Wilcox et al. (2009) found that a consumer's purchase intention for a counterfeit luxury brand is positively related to the extent to which this brand can help the consumer gain approval in social situations. On the other hand, based on responses from over a thousand Austrian consumers, researchers found that consumers avoid purchasing and using counterfeits at prices significantly lower than those of genuine brands only when perceived embarrassment potential is high (Penz and Stöttinger, 2005).

Similarly, Bian and Moutinho (2009) found that perceived social risks serve as a significant negative predictor for consumers' consideration of counterfeit luxury products. In addition, Penz and Stöttinger (2008) found that counterfeit users consider the similarity in physical appearance between a genuine and a counterfeit product is more important than the similarity in product quality. These studies have investigated influences of perceived social 
consequences on counterfeit consumption, however, little is known about how the likelihood of being detected affects the related consumer decisions.

\section{Pessimism Bias in Probability Estimation for Negative Events}

Prior research shows that people predict a negative event to be more likely to occur when it is perceived to be more severe (Pessimism Bias). For instance, Weber and Hilton (1990) asked their participants to assign numerical probabilities to the words that were supposedly used by their doctor to describe the chances of their developing a mild versus serious disease (e.g., gastric disturbances vs. skin cancer) during the next year. We found that people assign higher numerical probabilities to a given probability word (e.g., unlikely, possible, or probably) when it refers to an event perceived to be more negative (e.g., skin cancer).

Similarly, Verplanken (1997) presented participants with descriptions of hazards, as well as a numerical probability of hazard occurrence (i.e., 1:10;1:1,000; or 1:100,000) and asked participants to interpret each probability on verbally labelled scales, ranging from "very small" to "very large, He found that the participants judged a given probability as higher when it concerned hazards with catastrophe potential compared to non-catastrophic hazards.

More recently, Harris et al. (2009) showed their participants a cell matrix representing an apple orchard, with yellow cells referring to apple trees bearing "bad" apples and black cells to trees with "good" apples. Under different conditions of outcome severity, the bad apples were described as either being fatally poisonous or having an unpleasant taste. The cover story was about the orchard owner's young daughter who liked to play in the orchard and often picked apples from the trees to eat. Participants then provided a probability estimate of the young girl picking a bad apple if she randomly selected a tree. The actual percentage of bad apples was constant under all conditions. Consistent with earlier studies, Harris et al. (2009) found 
significantly higher probability estimates for the very severe outcome (i.e., fatally poisonous) compared to the less severe one (i.e., unpleasant taste).

In view of the above evidence, there seems to be a pessimism bias in probability estimates for a negative event, wherein the probability estimate of an uncertain, negative outcome is positively associated with the perceived severity of that outcome. In counterfeit consumption, because the outcome of being detected is likely to be associated with negative social consequences, it is expected that a pessimism bias may also exist under such a context. Specifically, we expect that if counterfeit consumers perceive the outcome of being identified as using counterfeit products to be more severe, they will predict a higher likelihood for this outcome to occur. This leads to the following hypothesis:

H1: Perceived outcome severity of being detected as using a counterfeit product has a positive effect on the probability estimate of being detected (Pessimism Bias).

\section{Mechanism Underlying the Effect of Outcome Severity}

An asymmetric-loss-function account is proposed to explain the effect of outcome severity on probability estimate (Weber, 1994). People can make two types of possible errors when they provide probability estimates for an uncertain event: underestimate or overestimate. Weber (1994) argues that the consequences associated with these two errors are different, and more importantly, people will bias their estimates to reduce the likelihood of making the more consequential error; for instance, underestimating the probability of getting skin cancer that could potentially result in death due to insufficient medical monitoring.

In contrast, overestimates of this probability may lead to greater monitoring, hence reducing the damage if the event really occurs and giving relief when the actual situation is better than expected. Many studies provide supporting evidence for this asymmetric-loss-function 
account by manipulating whether actions can be taken to prevent the negative event from occurring (e.g., Harris et al., 2009; Weber, 1994). However, this research also reveals that individuals do not overestimate the probability of a strongly negative event if they know nothing can be done to prevent it from occurring.

From the above discussion, it is unlikely that the asymmetric-loss-function account can explain the effect of outcome severity in counterfeit consumption as the outcome of being found out is largely uncontrollable. More importantly, this account does not explain exactly how outcome severity translates into the probability estimates for social judgments. In this regard, the spotlight effect literature provides an alternative and important perspective.

\section{Spotlight effect}

Spotlight effect refers to the tendency of people to believe that their actions, appearance, and internal states are more likely to be noticed by others than is actually the case (Gordon, 2013). For instance, people wearing T-shirts with an embarrassing image overestimate the probability of observers detecting and recalling the image (Gilovich et al., 2000). Likewise, people overestimate the extent to which others can discern their internal states; hence people telling lies in front of others overestimate the proportion of observers who can detect their deception (Gilovich et al., 1998).

People also think that their goals in a negotiation are more apparent to the negotiation partners than is actually the case (Mortensen and Neeley, 2012; Vorauer and Claude, 1998). Similarly, people overestimate the extent to which others can make accurate trait inferences about them from a sample of their behaviour (Vorauer and Ross, 1999). Spotlight effect occurs because people tend to overestimate the extent to which observers attend to them and fail to give 
sufficient consideration to situational factors that may moderate an observer's impression (Gilovich et al., 2000; Mortensen and Neeley, 2012).

\section{Mediating Role of Perceived Attention}

Although this line of research does not explicitly investigate how the biased estimates relate to the perceived severity of an outcome, some evidence exists to support such a relationship. First, people overestimate the likelihood of being detected when they are telling lies but not when they are telling the truth (Gilovich et al., 1998), suggesting that an individual may need to experience the internal state with some intensity in order for the spotlight effect to occur (Gilovich et al., 1998). In other words, the spotlight effect is more likely to occur when the outcome is perceived to be personally important (Gordon, 2013; Harris and Corner, 2011).

Second, the spotlight effect is not limited to negative outcomes, and it is also observed for positive outcomes of high personal importance. When wearing T-shirts bearing the images of figures of their own choices from popular culture (which suggests that the outcome of being detected is desirable), people still overestimate the probability of observers noticing the individuals depicted on the shirts (Gilovich et al., 2000). Hence, the valence (i.e., positive vs. negative) of the outcome does not seem to be very important. Again, the outcome importance may play a critical role in the spotlight effect.

In most cases of counterfeit consumption, because the outcome of being found out is accompanied by undesirable social consequences, such as losing favourable opinions of friends or being rejected by important reference groups, consumers may be worried about, or even fear of, being detected by others. Under such an intense state, the counterfeit users are likely to be influenced by the spotlight effect. That is, they may mistakenly perceive themselves as the focus of attention. More specifically, they tend to believe that most observers would attend to the key 
stimulus - the products being used - and hence find out that they are counterfeited. Based on the discussion, the following hypothesis is proposed:

H2: Positive effect of outcome severity on probability estimate is mediated by the perceived attention by the observers to the counterfeit product (Spotlight Effect).

\section{Moderating Role of Target Users (Self vs. Others)}

To further examine whether or not the spotlight effect explains the pessimism bias, we tested target person (self vs. other) as a boundary condition. Past studies attribute the spotlight effect to egocentric bias (Gilovich et al., 2000), or a tendency for people to focus greater attention on the self than on others in self-related judgments (Mortensen and Neeley, 2012; Ross and Sicoly, 1979). In other words, the spotlight effect is more likely to occur when the judgment is made for the self rather than for another person. Therefore, when a consumer is using a counterfeit product, the effect of outcome severity on probability estimate, which is attributable to the spotlight effect, should be weakened if someone else estimates the probability of being detected for this consumer.

The fact that another person is able to provide a more objective estimate is because the current focus is no longer the self, and hence, this person is less likely to be affected by the attention bias. In support of this, previous research has consistently documented systematic difference between decisions made for the self and decisions made for another person (e.g., Lee et al., 2008; Van Boven et al., 2000). To summarise, it is expected that the effect of outcome severity on counterfeit consumption is moderated by the target user of the counterfeit product. Hence, when the target user is another person, the effect of outcome severity will be attenuated because the spotlight effect is less likely to occur. This leads to the following hypothesis: 
H3: Positive effect of outcome severity on probability estimate is stronger when the target user is self, compared to when it is another person (Egocentric Bias).

\section{Mediated Moderation Effect of Perceived Attention}

The reason for the self-versus-other difference in decision making is that people find it difficult to fully take another person's perspective into account. When people are unable to anticipate how another person would feel in a different set of circumstances, it is hard for them to empathise with her/him who is actually experiencing those circumstances. Van Boven et al. (2000) showed that both product owners and buyers cannot accurately estimate the valuation of the product from the perspective of people in another role, and such egocentric empathy gaps cause the endowment effect, or the tendency to value an object more once one owns it. In contrast, people are able to reach a more objective judgment about a stimulus or an event when their perceptions are not biased by personal feelings. For instance, investors are found to make more rational decisions in stock transactions when the transactions involve others' stocks because they are personally indifferent to whether the stocks gain or lose (Lee et al., 2008).

If the effect of outcome severity on probability estimate is caused by biased perceptions of attention focus, the moderating effect of target user should be mediated by perceived attention. The individual (i.e., the judge) who provides probability estimate for another consumer is indifferent to whether or not the consumer would be detected, and hence, is not able to feel the nervousness or worries that the consumer may feel inside. Consequently, the judge is in a better position to form a more objective perception about how the attention of observers is allocated. The judge considers all the circumstantial factors that may distract observers' attention and has no reason to believe that the attention focus is shifted to the consumer or the counterfeit product. As a result, the probability estimate is less likely to be influenced by outcome severity. Hence, 
H4: Moderating influence of the type of target user on the positive effect of outcome severity on probability estimate is mediated by perceived attention.

\section{Counterfeit Purchase and Usage Intentions}

Extant research on counterfeit purchase and consumption shows that perceived social risks have a negative impact on consumers' purchase and usage intentions for counterfeit products such as software (Tan, 2002) and luxury watches (Bian and Moutinho, 2009). Similarly, social norms against counterfeiting (Wang, 2005) and social embarrassment (Penz and Stöttinger, 2005) have a negative impact on counterfeit purchase and usage. In view of the above, it is likely consumers estimating a higher probability of being detected as using a counterfeit product will exhibit a lower level of counterfeit purchase and usage intentions due to the presence of greater perceived social risks. Hence, we propose:

H5: Probability estimate of being detected has a negative effect on a) purchase intention and b) usage intention for counterfeit products.

Figure 1 summarises the conceptual framework and all the hypothesised relationships.

$<$ Insert Figure 1 about here $>$

\section{STUDY 1: OUTCOME SEVERITY AND PROBABILITY ESTIMATE}

\section{Sample and Procedure}

We used Study 1 to test the main effect (H1) with undergraduate student participants $(\mathrm{N}=36$, male $=69 \%)$ recruited from a research participant pool at a Hong Kong university. They signed up in advance for a "Consumer Study" and received a dining coupon worth US\$3 for their participation. They came to a classroom at a particular time slot to complete a questionnaire. About two-third (64\%) of them reported that they had purchased counterfeits in the past. 
A hypothetical brand, Brand X, was used in this study to control for product familiarity and product evaluation (of the genuine product). Product familiarity may influence probability estimate because counterfeit users who are highly familiar with the product know what a genuine product should look like, and this knowledge might result in an overestimate of the difference between a counterfeit and a genuine product, which in turn, may lead to a high probability estimate. Product evaluation can also influence probability because preference for a genuine product is negatively related to the evaluation of its faked counterpart (Commuri, 2009), and unfavourable evaluation of the counterfeit can result in a high probability estimate.

Another variable that may influence probability is the purchase/usage history of counterfeit products. Past usage of counterfeits has a positive effect on their consumption (Penz and Stöttinger, 2005). Consumers who have purchased and used counterfeits before are also likely to feel more comfortable with counterfeit consumption (Furnham and Valgeirsson, 2007; Tom et al., 1998), and therefore, may underestimate probability. Hence, purchase history of counterfeits was measured in all the studies and included as a control variable in data analysis.

Participants first read the following scenario with information about Brand X: "There is a well-known brand of jeans in Australia, and it has not been introduced into the Asian market. Because the company does not want to disclose the name, let's call it Brand X here. Jeans of Brand $\mathrm{X}$ are very popular among young adults in Australia because of its design and fine quality. However, there are many counterfeit X jeans in the local market. If you don't examine and compare them closely, counterfeit X jeans look very similar to genuine X jeans. However, after conducting extensive market research, the company detects some difference between genuine and counterfeit X jeans". Participants then saw a close-up view of the focal attribute in the genuine as well as in the counterfeit jeans (Figure 2), along with a verbal description of the 
difference in this attribute between the two jeans. We selected 'belt loops' as an attribute with moderate usefulness in detecting a counterfeit jeans $($ Mean $=3.47, \mathrm{SD}=1.49)$ based on a pre-test with thirty participants from the same participant pool who rated 11 attributes of jeans on a scale of 1-7 in terms of the usefulness of each attribute in identifying counterfeit jeans.

$<$ Insert Figure 2 about here $>$

Next, participants received the following instructions: "Please close your eyes, and imagine that you are wearing a pair of counterfeit $X$ jeans. Will others find out that this pair of jeans is counterfeit (assuming others are aware of the difference indicated above between counterfeit and genuine jeans)?" Because the brand was hypothetical, participants were told that the observers had full knowledge about the attribute difference. Thus, they were ensured that the observers would be able to find out that the jeans were counterfeit as long as they noticed what the attribute looked like on the participant's jeans.

\section{Measures}

The participants were asked to pause after reading the above instructions and write down all their thoughts as they imagined themselves to be in the scenario. Next, participants were asked to use a scale ranging from 0 (not likely at all) to 10 (very likely) to answer the following question: "How likely do you think the people around (e.g., the classmates and friends) will find out that your jeans are counterfeit through daily interaction (e.g., attending lectures together or chatting)?" Outcome severity was measured by having participants indicate the extent to which the outcome of being detected would make them feel embarrassed, hurt their public images, lose their faces, and make them feel badly. After completing these measures, participants reported whether they had purchased counterfeit products before and, if yes, specified the product categories along with their gender and age. 


\section{Results and discussion}

The four items measuring outcome severity were averaged to form a severity index $(\alpha=$ .97). A linear regression analysis with probability estimate (Mean $=3.97, \mathrm{SD}=2.34$ ) as the dependent variable, and severity (mean-cantered, Mean $=4.41, \mathrm{SD}=1.75)$ as the explanatory variables revealed a significant effect for severity $\left(\beta=.35, t=2.16, p<.05\right.$, adjusted $\left.\mathrm{R}^{2}=.10\right)$. Thus, a positive effect of outcome severity on probability estimate was found (H1). Purchase history did not show significant effects after being added to the above regression model.

By using a hypothetical product and controlling for other potentially confounding factors, Study 1 demonstrates that users of counterfeits are prone to a pessimism bias in generating probability estimates for being detected by others. The next two studies explored the process underlying this effect and tested target person (self vs. other) as a boundary condition under which the bias was attenuated. Study 2 and 3 used real products and brands to increase the external validity of the findings.

\section{STUDY 2: MEDIATING ROLE OF PERCEIVED ATTENTION}

This study used a one-factor, between-subjects design with the outcome severity manipulated (low vs. high). Study 1 measured outcome severity, but the observed effects may be subject to alternative explanations provided by other unmeasured, but associated factors (Ahluwalia et al., 2000). As the perceived severity of being detected for using counterfeits may vary among different observers, we used a pre-test with university students $(\mathrm{N}=20)$ from the same participant pool to evaluate the severity of being detected by a stranger, an old friend, a new friend, a cousin, and a previous teacher in high school. A repeated measures ANOVA analysis showed that the perceived outcome severity varied among different observers $(F(4,76)$ 
$=5.81, p<.05)$. In order to better control the familiarity level between the user and the observer, we selected a stranger $($ Mean $=4.50)$ and a new friend $($ Mean $=5.75)$ as the observer under the low-severity and the high-severity condition, respectively.

\section{Sample and Procedure}

Participants for Study $2(\mathrm{~N}=64$, male $=37 \%)$ were recruited from a research pool using the same method as for the participants in Study 1. Three-fourth $(75 \%)$ of them reported that they had purchased counterfeit products in the past. A new stimulus - a Ralph Lauren polo shirt (hereafter referred to 'RLPS') - was used. Product familiarity and product evaluation were measured to control for their effects. A pre-test was conducted among university students $(\mathrm{N}=$ 34) from the same participant pool to test their general knowledge about RLPS and the diagnosticity of the logo in identifying a counterfeit shirt. Results show that 32 out of 34 participants had seen or heard about RLPS before, hence the participants were quite familiar with the stimulus.

We also asked participants to imagine the following scenario: "You see a person wearing a Ralph Lauren polo shirt. The shirt looks very much like a genuine Ralph Lauren polo shirt, except that you notice that the logo on that shirt is not embroidered and therefore looks quite plain." Then we asked them to indicate the extent to which they would judge the shirt as a counterfeit. On a scale of 1 to 7 , the mean value for the judgment variable was 4.86 , significantly different from $4(t(31)=4.30, p<.001)$, hence participants were able to infer the fakeness of the shirt based on the logo feature, which shows sufficient attribute diagnosticity.

The scenario was similar to Study 1, albeit with several modifications. First, the number of observers and the interaction between the target user and the observer were better defined. Second, because in most cases users of counterfeit products have no information about the ability 
of an observer to distinguish between a counterfeit and a genuine product, such information was not provided in Study 2 and participants had to form the assessment on their own. Third, we asked the participants to indicate their purchase and usage intentions of the counterfeit product so that we could examine the influence of probability estimates on consumption behaviours.

At the beginning, participants were asked to imagine the following scenario: "You are having afternoon tea in a restaurant, and wearing a counterfeit Ralph Lauren polo shirt. The shirt looks exactly like a genuine Ralph Lauren polo shirt, except that the polo logo on the counterfeit shirt was not embroidered and looked quite plain." After the difference between the counterfeit shirt and its genuine counterpart was described, the scenario continued to introduce different observers. Under the low severity condition, the scenario continued with "When you are sitting alone in the restaurant, a person that you do not know comes to your table. He introduces that he works for a marketing research company and his company is conducting a research on diet habits of Hong Kong residents. He asks if he could talk with you for 10 minutes. You agree. He sits down and you two start the conversation". Under the high severity condition, the scenario continued with "When you are sitting alone, a person enters the restaurant. You recognise him as a friend that you just met at a party two weeks ago. You two shared mobile numbers at the party, and since then you have talked with him on the phone for a couple of times and were planning to meet again. The friend also sees you and comes to chat with you. You two talk for 10 minutes." The scenario ended by asking participants the question of "Do you think the person/friend would find out that your polo shirt is counterfeited?" Along with these instructions, the pictures of a genuine RLPS and a close-up view of the polo logo were presented. A big-pony RLPS was used so that the logo was salient and clear. Participants imagined being in the described scenario for 30 seconds and were asked to write down their thoughts. 


\section{Measures}

The dependent measures were similar to those in Study 1 except that a few new constructs were added. Following probability estimate, overall evaluations of a genuine RLPS were measured using a semantic differential scale with five items "good, likable, favourable, attractive, and desirable". After that, outcome severity was assessed, followed by the product familiarity measure. Product familiarity was tapped by requesting participants to indicate the extent to which they "were familiar with, could recognise, and had heard of RLPS" (BeckerOlson, 2003). Next, perceived attention was measured using items adopted from Bruner and Anand (2000) and participants indicated the extent to which they thought the observer would "pay attention to, notice, and look at the shirt" during the conservation. Purchase intention and usage intention were respectively measured by having participants indicate the extent to which they would purchase a RLPS as described in the scenario if they happened to see it sold at a reasonable price, and the extent to which they would wear it if they happened to have one. Except for the probability prediction, seven-point scales were used for all responses. Finally, purchase history and demographic measures were collected.

\section{Results and discussion}

To check the manipulation of outcome severity, an ANOVA analysis was conducted on the severity index $(\alpha=.93$, Mean $=5.03, \mathrm{SD}=1.33)$, and results indicated that the manipulation was effective: $F(1,62)=4.20, p<.05$ (outcome severity low $=4.69$, outcome severity high $=$ 5.36). To test the mediating role of perceived attention, an index of attention was generated ( $\alpha=$ .88 , Mean $=4.15, \mathrm{SD}=1.21)$ and the analysis followed the procedure recommended by Baron and Kenny (1986). Probability estimate $(\mathrm{Mean}=4.84, \mathrm{SD}=2.01)$ was first regressed on severity (dummy variable) and a significant effect of severity was revealed $(\beta=.33, t=2.74, p<.01$ ), 
thereby supporting H1. Attention was then regressed on severity and again the effect was significant $(\beta=.27, t=2.20, p<.05)$. Next, both severity and attention were included in the regression to explain probability estimate and the results indicated that severity fell below significance whereas attention was still significant $(\beta=.58, t=5.69, p<.001)$. The Sobel's test (1982) was also significant (Sobel test statistic $=2.06, p<.05$ ). These findings support H2 and show that perceived attention mediated the effect of outcome severity on probability estimate.

The mediating effect of perceived attention remained valid after product familiarity $(\alpha=$ .68 , Mean $=4.40, \mathrm{SD}=1.25)$, product evaluation $(\alpha=.90$, Mean $=4.50, \mathrm{SD}=.97)$ and purchase history were incorporated into the model as control variables. Product familiarity showed a significant positive effect on both probability estimate $(\beta=.30, t=2.46, p<.05)$ and perceived attention $(\beta=.38, t=3.19, p<.01)$, suggesting that the participants who were more familiar with RLPS perceived more attention and estimated a higher probability. Results also support H5a and $\mathrm{H} 5 \mathrm{~b}$ by showing that the probability estimate was negatively related to both purchase intention $(\beta$ $=-.23, t=-1.80, p<.08)$ and usage intention $(\beta=-.41, t=-3.40, p<.01)$ after controlling for the effects of product familiarity, product evaluation, and purchase history.

Study 2 provides supporting evidence that counterfeit users tend to predict a higher likelihood of being detected when the observer is of higher relevance, and hence, the detection is more consequential. The biased estimate is caused by a self-focused attention shift and an overestimate of the prominence of the counterfeit product. The next study further tested whether the spotlight effect was the underlying force for the effect of outcome severity by investigating the target person (self vs. other) as a boundary condition for the pessimism bias. Specifically, it examined if consumers may overestimate the probability of being detected if they rather than others were under observation. 


\section{STUDY 3: EGOCENTRIC NATURE OF PESSIMISM BIAS}

\section{Sample and Procedure}

Study 3 used a one-factor, between-subjects design with the target manipulated (self vs. others) with the participants recruited in the same way as in the first two studies $(\mathrm{N}=133$, male $=42 \%)$. About three-fourth (73\%) reported having purchased counterfeit products in the past. The scenario was very similar to that of the high-severity condition in Study 2 (i.e., a friend as an observer). When the target was another person, participants imagined that another university student was wearing the counterfeit RLPS, and were asked to assess outcome severity for the student. The stimulus was the same as that of Study 2 .

\section{Results and discussion}

We conducted mediation and mediated moderation analyses following the six steps that Muller et al. (2005) advocate. Models 1-3 tested the mediating role of perceived attention (PA) in the effect of outcome severity (OS) on probability estimate (PE).

(1) $\mathrm{PE}=\beta_{10}+\beta_{11} \mathrm{OS}+\varepsilon_{1}$,

(2) $\mathrm{PA}=\beta_{20}+\beta_{21} \mathrm{OS}+\varepsilon_{2}$,

(3) $\mathrm{PE}=\beta_{30}+\beta_{31} \mathrm{OS}+\beta_{32} \mathrm{PA}+\varepsilon_{3}$.

$<$ Insert Table 1 about here $>$

The results are reported in Table 1 . The effect of severity on probability estimate, $\beta_{11}$, was significant; the effect of severity on perceived attention, $\beta_{21}$, was also significant; when attention was added to explain probability (model 3), the effect of attention, $\beta_{32}$, was still significant, but the effect of severity fell below significance. Thus, the effect of outcome severity 
on probability estimate was fully mediated by perceived attention (H2). Models 4-6 tested the mediated moderation role of the target. The target was coded as a dummy variable (self $=1$ ).

(4) $\mathrm{PE}=\beta_{40}+\beta_{41} \mathrm{OS}+\beta_{42}$ target $+\beta_{43} \mathrm{OS} \times$ target $+\varepsilon_{4}$,

(5) $\mathrm{PA}=\beta_{50}+\beta_{51} \mathrm{OS}+\beta_{52}$ target $+\beta_{53} \mathrm{OS} \times$ target $+\varepsilon_{5}$,

(6) $\mathrm{PE}=\beta_{60}+\beta_{61} \mathrm{OS}+\beta_{62}$ target $+\beta_{63} \mathrm{OS} \times$ target $+\beta_{64} \mathrm{PA}+\beta_{65} \mathrm{PA} \times \operatorname{target}+\varepsilon_{6}$.

To establish a mediated moderation effect, evidence was first needed for an overall moderating effect of the target. In model 4 , the coefficient for the interaction between outcome severity and target, $\beta_{43}$, was significant, supporting $\mathrm{H} 3$ about the overall moderating role of target. Then, the question was whether the mediating process accounts for the moderation effect. In model 5, results showed that the effect of severity on attention was moderated by target (i.e., $\beta_{53}$ was significant), and in model 6 , the average partial effect of attention on probability $\left(\beta_{64}\right)$ was also significant. As a result, the moderation of the residual effect of severity, $\beta_{63}$, was reduced in magnitude compared to the moderation of the overall effect of severity, $\beta_{43}$. These results suggest that attention fully mediates the moderating role of target, thus supporting H4.

Similar to Study 2, probability estimate was negatively related to both purchase intention $(\beta=-.12, t=-2.10, p<.05)$ and usage intention $(\beta=-.19, t=3.48, p<.01)$ after the effects of product familiarity, product evaluation, and purchase history were controlled. However, these control variables did not show any effects on probability estimate or perceived attention. Overall, Study 3 shows that the pessimism bias - probability estimates increase as the outcome is perceived as more severe - is egocentric in nature, thereby providing further evidence that the perceived attention from observers drives the effect of outcome severity. Next, we discuss our findings along with their theoretical contribution and managerial implications. 


\section{DISCUSSION AND CONTRIBUTION}

Our research contributes to the growing literature on counterfeit consumption by pointing out an important, but previously overlooked, factor that influences consumer decision making, namely the probability of being detected by significant others. According to expected utility theory (Tversky, 1967), the expected utility of an outcome is determined by two factors, the subjective value of the outcome and the probability of that outcome to occur. For example, when deciding whether or not to carry an umbrella, an individual may consider two factors: (1) consequences of being caught in rain; and (2) the probability that rain will occur (Harris et al., 2009. Despite what this classic theory advocates, current research on counterfeit consumption has focused mostly on the first factor or the negative social consequences of such consumption. Consequently, the second factor or how likely the focal counterfeit user would be detected as using a counterfeit product by others has been neglected in the literature.

This paper is among the first to explore the role of probability estimate in counterfeit consumption and to provide empirical evidence that this estimate negatively influences both purchase intention and usage intention. Hopefully, this work can provide new insights into the puzzle of why consumers knowingly continue to purchase and use counterfeit products despite the social risks of being found out. Our results also shed new light on the mixed findings reported in previous research about the influence of social risks on counterfeit purchase. For instance, Penz and Stöttinger (2005) found that embarrassment potential influenced purchase intention of counterfeits sold at significantly lower rather than slightly lower prices.

One plausible explanation for this difference is that counterfeits at slightly lower prices are generally quite similar to genuine products in physical appearance and quality, and hence, have low chances of being detected as counterfeits. Therefore, social consequences of being 
detected, such as embarrassment or loss of respect, may not be the major concerns in such purchase decisions. Likewise, Wee et al. (1995) found that risk-taking had no effect on purchase intention of counterfeits, and hence, concluded that consumers might not really understand the risks involved in counterfeit purchase. The findings derived from the present research suggest another plausible explanation for these results. Specifically, Wee et al. (1995) asked their participants to provide purchase intention for four common product categories - books, software, leather wallets/purses and watches - without any information about what these counterfeit products were or how they were different from their genuine counterparts. Thus, participants were unable to assess the likelihood of being detected as using counterfeits, and even if they were aware of the possible negative consequences of being detected, they could not estimate how likely those consequences would actually occur. This may help explain why their purchase intention failed to capture individual differences in risk taking.

While probability estimate is an independent factor that should not be neglected when assessing the impact of social consequences on counterfeit consumption, this research further demonstrates that probability estimate is influenced by social consequences. In other words, it is suggested that perceived social consequences may have "dual effects" on consumers' purchase and usage of counterfeit products. One effect is, if consumers think the consequences of being detected are devastating, they may avoid using counterfeit products even without considering the chances of being detected. The other effect is, as this research shows, the perceived severity of social consequences can also bias probability estimate so that the more they do not want to be found out, the higher probability they estimate. This higher probability estimate will, in turn, dampen their intention to purchase and use counterfeits. Our findings provide useful insights into how social consequences may influence consumers' decisions on counterfeit consumption. 
Our research also contributes to the spotlight effect literature by identifying a new antecedent, that is, the perceived severity of an outcome. Previous research has observed the spotlight effect under different circumstances, such as wearing embarrassing T-shirts, telling lies in front of others, and hiding negotiation goals. However, these contexts are quite diverse and the spotlight effect was not observed in some of them (e.g., telling truth to others, Gilovich et al., 1998). Identifying outcome severity as an antecedent will help synthesise previous studies and advance understanding of the conditions under which the spotlight effect is more or less salient. Although the present study focuses on a negative outcome (i.e., being recognised as users of counterfeit products), some prior socio-psychological research has reported that the effect can also be triggered by positive outcomes or events deemed as important (e.g., Gilovich et al., 2000). To further test the generalizability of the present findings, future research should investigate if the spotlight effect can really be triggered by positive outcomes (e.g., being admired by others) within the context of counterfeit consumption.

\section{MANAGERIAL IMPLICATIONS}

Besides its conceptual contributions, our research also has several important managerial implications. First, despite their widespread efforts, marketers of well-known genuine brands have failed to curtail counterfeit consumption, possibly due to a lack of understanding about its complex socio-psychological motivations. Many anti-counterfeiting campaigns focus on the ethicality of counterfeit consumption and intend to raise consumer awareness about intellectual property protection (e.g., the Japan Patent Office 2009 anti-counterfeiting commercial). However, we argue that genuine brand managers could also emphasise the importance of buying and using authentic products by educating consumers about the adverse effects of using 
counterfeits. This could be achieved by highlighting the spotlight effect and the role of outcome severity and egocentric bias in probability estimation.

Specifically, our findings suggest that genuine brand managers should emphasise the negative social consequences of using counterfeits in their marketing communications campaigns. More campaigns should be launched to increase consumer awareness of social risks associated with counterfeit consumption, such as losing the favourable opinions of friends or being rejected by important reference groups. This strategy may be particularly effective in Asian countries with collectivist cultures where people are highly concerned about impression made on others. Notably, some of these countries (e.g., China, Thailand) are heavy markets for counterfeit products. As part of their advertising and communication efforts, genuine brand marketers, for example, may feature their anti-counterfeiting advertisements with a social gathering in which some peer group members or friends share with others their embarrassing experience associated with prior counterfeit consumption. The use of important referents to disseminate the relevant negative social consequences would further strengthen the effectiveness of the anti-counterfeiting message.

Moreover, in view of the deterrent effect of perceived outcome severity and probability estimate of being detected on counterfeit consumption reported in this research, genuine brand marketers may further fine-tune their anti-counterfeiting campaigns accordingly. For instance, other than negative social consequences, they may also emphasise the potential legal liabilities (e.g., infringement of intellectual property rights under civil laws) consumers need to bear in case of being detected as using counterfeits. Likewise, these brand marketers can better protect their brands by familiarizing consumers with their products and the essential product features. By educating consumers on how to distinguish between a genuine brand and its counterfeit version, 
marketers would be able to alter potential counterfeit consumers' probability estimate of being detected, and consequently, discourage them from involving in such consumption.

\section{LIMITATIONS AND FUTURE RESEARCH}

This study also has a few limitations that may be addressed in future research. First, the sample used in this research is confined to university students. Although previous research shows that students constitute an important group of counterfeit users (Prendergast et al., 2002; Sharma and Chan, 2011), caution must be taken when the results of this research are generalised to other consumer groups. Future research involving non-student samples will be helpful in replicating our findings. Second, participants in the three experiments were informed the difference between the genuine product and its counterfeit counterpart. It is unknown without further testing whether or not the findings will still hold when users are completely unaware of the difference. However, this concern appears grounded. Compared with their Western counterparts, Chinese consumers have rather limited experience with luxury brands (Kapferer and Bastien, 2009; Zhan and He, 2012), and therefore, may not have adequate knowledge to distinguish a counterfeit product from a genuine one. Their prediction under these circumstances is thus unclear.

On the one hand, it is possible for a counterfeit product user to be affected by a similar spotlight effect, because they think there must be some difference between a $\$ 30$ and a $\$ 300 \mathrm{~T}$ shirt although they do not know what exactly the difference is; and on the other hand, the consumer may really have no idea about the subtle difference between a genuine and a counterfeit product (e.g. the logo is embroidered or not), and naively believe that the two products have the same appearance. In this case, the consumer does not necessarily exhibit the pessimism bias. It is likely that the conditions underlying the occurrence of these two possible results depend on other factors, such as consumer personality, perceived product knowledge of 
observers, and perceived difficulty in making a physically identical counterfeit. The possible interacting effects of these factors present a fruitful avenue for future research. Finally, more research is needed on the process underlying consumer assessment of being found out for using counterfeits. For instance, it would be useful to explore other factors that may influence counterfeit consumers' perceived outcome severity such as the original price of the genuine product and the type of product (e.g., utilitarian vs. hedonic).

\section{REFERENCES}

Ahluwalia, R., Burnkrant, R.E. and Unnava, H.R. (2000), “Consumer response to negative publicity: The moderating role of commitment", Journal of Marketing Research, Vol. 37 No. 2, pp. 270-79.

Baron, R.M. and Kenny, D.A. (1986), "The moderator-mediator variable distinction in social psychological research: Conceptual, strategic, and statistical considerations", Journal of Personality and Social Psychology, Vol. 51 No. 6, pp. 1173-82.

BASCAP (2011), Estimating the Global Economic and Social Impacts of Counterfeiting and Piracy, Frontier Economics Limited, London.

Becker-Olson, K.L. (2003), “And now, a word from our sponsor: A look at the effects of sponsored content and banner advertising", Journal of Advertising, Vol. 32 No. 2, pp. 1732.

Bian, X. and Moutinho, L. (2009), “An investigation of determinants of counterfeit purchase consideration", Journal of Business Research, Vol. 62 No. 3, pp. 368-78.

Bian, X. and Moutinho, L. (2011), "The role of brand image, product involvement, and knowledge in explaining consumer purchase behaviour of counterfeits: Direct and indirect effects", European Journal of Marketing, Vol. 45 Nos. 1/2, pp. 191-216. 
Bloch, P.H., Bush, R.F. and Campbell, L. (1993), “Consumer 'accomplices' in product counterfeiting: A demand-side investigation”, Journal of Consumer Marketing, Vol. 10 No. 4, pp. 27-36.

Bruner II, C.G. and Anand, K. (2000), "Web commercials and advertising hierarchy-of-effects", Journal of Advertising Research, Vol. 40 Nos. 1/2, pp. 35-42.

Cheung, W. and Prendergast, G. (2006), "Buyers' perceptions of pirated products in China", Marketing Intelligence \& Planning, Vol. 24 No. 5, pp. 446-62.

Commuri, S. (2009), “The impact of counterfeiting on genuine-item consumers' brand relationships", Journal of Marketing, Vol. 73 No. 3, pp. 86-98.

d'Astous, A. and Gargouri, E. (2001), “Consumer evaluations of brand imitations”, European Journal of Marketing, Vol. 35 Nos. 1/2, pp. 153-67.

Eisend, M., and Schuchert-Güler, P. (2006), "Explaining counterfeit purchases: A review and preview", Academy of Marketing Science Review, Vol. 12 No. 6, pp. 1-25.

Furnham, A. and Valgeirsson, H. (2007), "The effect of life values and materialism on buying counterfeit products", Journal of Socio-Economics, Vol. 36 No. 5, pp. 677-85.

Gilovich, T., Medvec, V.H. and Savitsky, K. (2000), "The spotlight effect in social judgment: An egocentric bias in estimates of the salience of one's own actions and appearance", Journal of Personality and Social Psychology, Vol. 78 No. 2, pp. 211-22.

Gilovich, T., Savitsky, K. and Medvec, V.H. (1998), “The illusion of transparency: Biased assessments of others' ability to read one's emotional states", Journal of Personality and Social Psychology, Vol. 75 No. 2, pp. 332-46. 
Gordon, A. M. (2013), “Have you fallen prey to the spotlight effect?” Psychology Today, November 21, available at http://www.psychologytoday.com/blog/between-you-andme/201311/have-you-fallen-prey-the-spotlight-effect (accessed 21 July 2014).

Grossman, G.M. and Shapiro, C. (1988), "Counterfeit-Product Trade”, American Economic Review, Vol. 78 No. 1, pp. 59-75.

Harris, A.J.L. and Corner, A. (2011), "Communicating environmental risks: Clarifying the severity effect in interpretations of verbal probability expressions", Journal of Experimental Psychology: Learning, Memory and Cognition, Vol. 37 No. 6, pp. 1571-78.

Harris, A.J.L., Corner, A. and Hahn, U. (2009), "Estimating the probability of negative events", Cognition, Vol. 110 No. 1, pp. 51-64.

Harvey, P.J. and Walls, D. (2003), "Laboratory markets in counterfeit goods: Hong Kong versus Las Vegas", Applied Economics Letters, Vol. 10 No. 14, pp. 883-7.

Kapferer, J.N. and Bastien, V. (2009), The Luxury Strategy: Breaking the Rules of Marketing to Build Luxury Brands, Kogan Page, London.

Lacanilao, R. D., Cash, S. B. and Adamowicz, W. L. (2011), "Heterogeneous consumer responses to snack food taxes and warning labels", Journal of Consumer Affairs, Vol. 45 No. 1, pp. 108-22.

Lee, H., Park, J., Lee, J. and Wyer, R.S. (2008), "Disposition effects and underlying mechanisms in E-trading of stocks", Journal of Marketing Research, Vol. 45 No. 3, pp. 362-78.

Mortensen, M. and Neeley, T. B. (2012), "Reflected knowledge and trust in global collaboration", Management Science, Vol. 58 No. 12, pp. 2207-24.

Muller, D., Judd, C.M. and Yzerbyt, V.Y. (2005), "When moderation is mediated and mediation is moderated", Journal of Personality and Social Psychology, Vol. 89 No. 6, pp. 852-63. 
Penz, E. and Stöttinger, B. (2005), 'Forget the 'real' thing - take the copy! An explanatory model for the volitional purchase of counterfeit products", Advances in Consumer Research, Vol. 32, pp. 568-75.

Penz, E. and Stöttinger, B. (2008), "Corporate image and product similarity - Assessing major demand drivers for counterfeits in a multi-country study", Psychology \& Marketing, Vol. 25 No. 4, pp. 352-81.

Prendergast, G., Chuen, L.H., and Phau, I. (2002), “Understanding consumer demand for nondeceptive pirated brands", Marketing Intelligence \& Planning, Vol. 20 No. 7, pp. 405-16.

Ross, M. and Sicoly, F. (1979), "Egocentric biases in availability and attribution", Journal of Personality and Social Psychology, Vol. 37 No. 3, pp. 322-36.

Russell, D. W. and Russell, C. A. (2010), "Here or there? Consumer reactions to corporate social responsibility initiatives: Egocentric tendencies and their moderators", Marketing Letters, Vol. 21 No. 1, pp. 65-81.

Savitsky, K., Epley, N. and Gilovich, T. (2001), "Do others judge us as harshly as we think? Overestimating the impact of our failures, shortcomings, and mishaps", Journal of Personality and Social Psychology, Vol. 81 No. 1, pp. 44-56.

Schembri, S., Merrilees, B. and Kristiansen, S. (2010), "Brand consumption and narrative of the self”, Psychology \& Marketing, Vol. 27 No. 6, pp. 623-38.

Sharma, P. and Chan, R.Y.K. (2011), "Counterfeit proneness: Conceptualization and scale development”, Journal of Marketing Management, Vol. 27 Nos. 5/6, pp. 602-26.

Sobel, M. E. (1982), “Asymptotic confidence intervals for indirect effects in structural equation models", in Leinhart, S. (eds.) Sociological Methodology, Jossey-Bass, San Francisco, CA, pp. 290-312. 
Staake, T., Thiesse, F. and Fleisch, E. (2009), "The emergence of counterfeit trade: a literature review", European Journal of Marketing, Vol. 43 Nos. 3/4, pp. 320-49.

Swike, E., Thompson, S. and Vasquez, C. (2008), "Privacy in China", Business Horizons, Vol. 51 No. 6, pp. 493-500.

Tan, B. (2002), "Understanding consumer ethical decision making with respect to purchase of pirated software", Journal of Consumer Marketing, Vol. 19 No. 2, pp. 96-111.

Tom, G., Garibaldi, B., Zeng, Y. and Pilcher, J. (1998), "Consumer demand for counterfeit goods", Psychology \& Marketing, Vol. 15 No. 5, pp. 405-421.

Trinh, V.D. and Phau, I. (2012), "The overlooked component in the consumption of counterfeit luxury brands studies: Materialism - a literature review", Contemporary Management Research, Vol. 8 No. 3, pp. 251-64.

Turunen, L.L.M., and Laaksonen, P. (2011), "Diffusing the boundaries between luxury and counterfeits", Journal of Product \& Brand Management, Vol. 20 No. 6, pp. 468-74.

Tversky, A. (1967), “Additivity, utility and subjective probability”, Journal of Mathematical Psychology, Vol. 4, pp. 175-202.

Van Boven L., Dunning, D. and Loewenstein, G. (2000), "Egocentric empathy gaps between owners and buyers: Misperceptions of the endowment effect", Journal of Personality and Social Psychology, Vol. 79 No. 1, pp. 66-76.

Verplanken, B. (1997), "The effect of catastrophe potential on the interpretation of numerical probabilities of the occurrence of hazards", Journal of Applied Social Psychology, Vol. 27 No. 16, pp. 1453-67.

Vorauer, J.D. and Claude, S.D. (1998), "Perceived versus actual transparency of goals in negotiation", Personality and Social Psychology Bulletin, Vol. 24 No. 4, pp. 371-85. 
Vorauer, J.D. and Ross, M. (1999), "Self-awareness and transparency overestimation: Failing to suppress one's self”, Journal of Experimental Social Psychology, Vol. 35 No. 5, pp. 41540.

Wang, C.C. (2005), "Factors that Influence the Piracy of DVD/VCD Motion Pictures", Journal of American Academy of Business, Vol. 6 No. 2, pp. 231-37.

Weber, E.U. (1994), "From subjective probabilities to decision weights: The effect of asymmetric loss functions on the evaluation of uncertain outcomes and events", Psychological Bulletin, Vol. 115 No. 2, pp. 228-42.

Weber, E.U. and Hilton, D. (1990), "Contextual effects in the interpretations of probability words: Perceived base-Rate and severity of events", Journal of Experimental Psychology: Human Perception \& Performance, Vol. 16 No. 4, pp. 781-89.

Wee, C.H., Tan, S.J. and Cheok, K.H. (1995), "Non-price determinants of intention to purchase counterfeit goods: An exploratory study”, International Marketing Review, Vol. 12 No. 6, pp. 19-46.

Wilcox, K., Hyeong, M.K. and Sen, S. (2009), "Why do consumers buy counterfeit luxury brands", Journal of Marketing Research, Vol. 46 No. 2, pp. 247-59.

Yoo, B. and Lee, S-H. (2009), "Buy genuine luxury fashion products or counterfeits?”, Advances in Consumer Research, Vol. 36, pp. 280-6.

Zhan, L. and He, Y. (2012), "Understanding luxury consumption in China: Consumer perceptions of best-known brands", Journal of Business Research, Vol. 65 No. 10, pp. $1452-60$

Zimmerman, A. (2013), "Contending with Chinese counterfeits: Culture, growth and management responses", Business Horizons, Vol. 56 No. 2, pp. 141-148. 
Figure 1 - Conceptual Framework

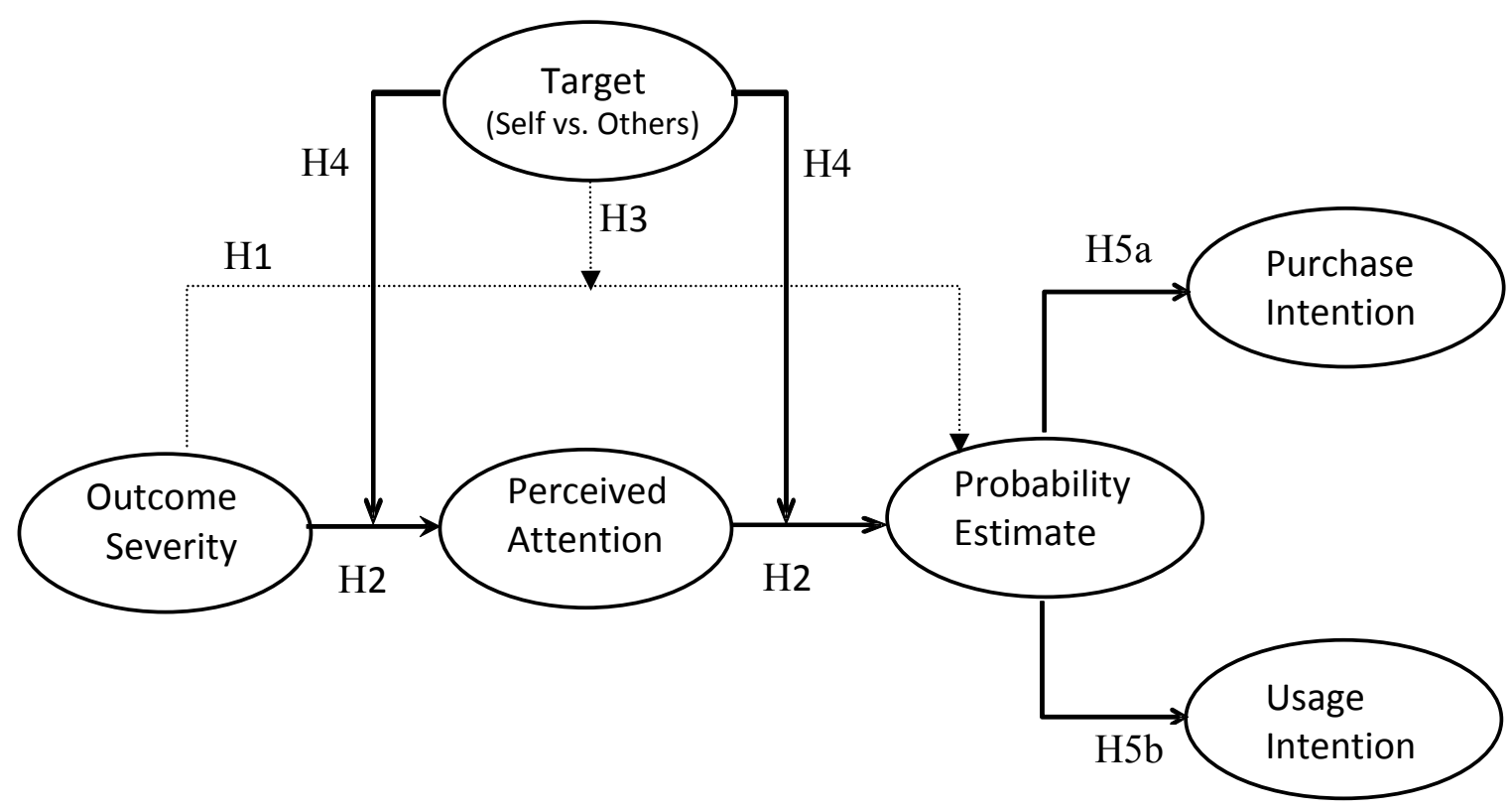


Figure 2 - Stimuli for Study 1

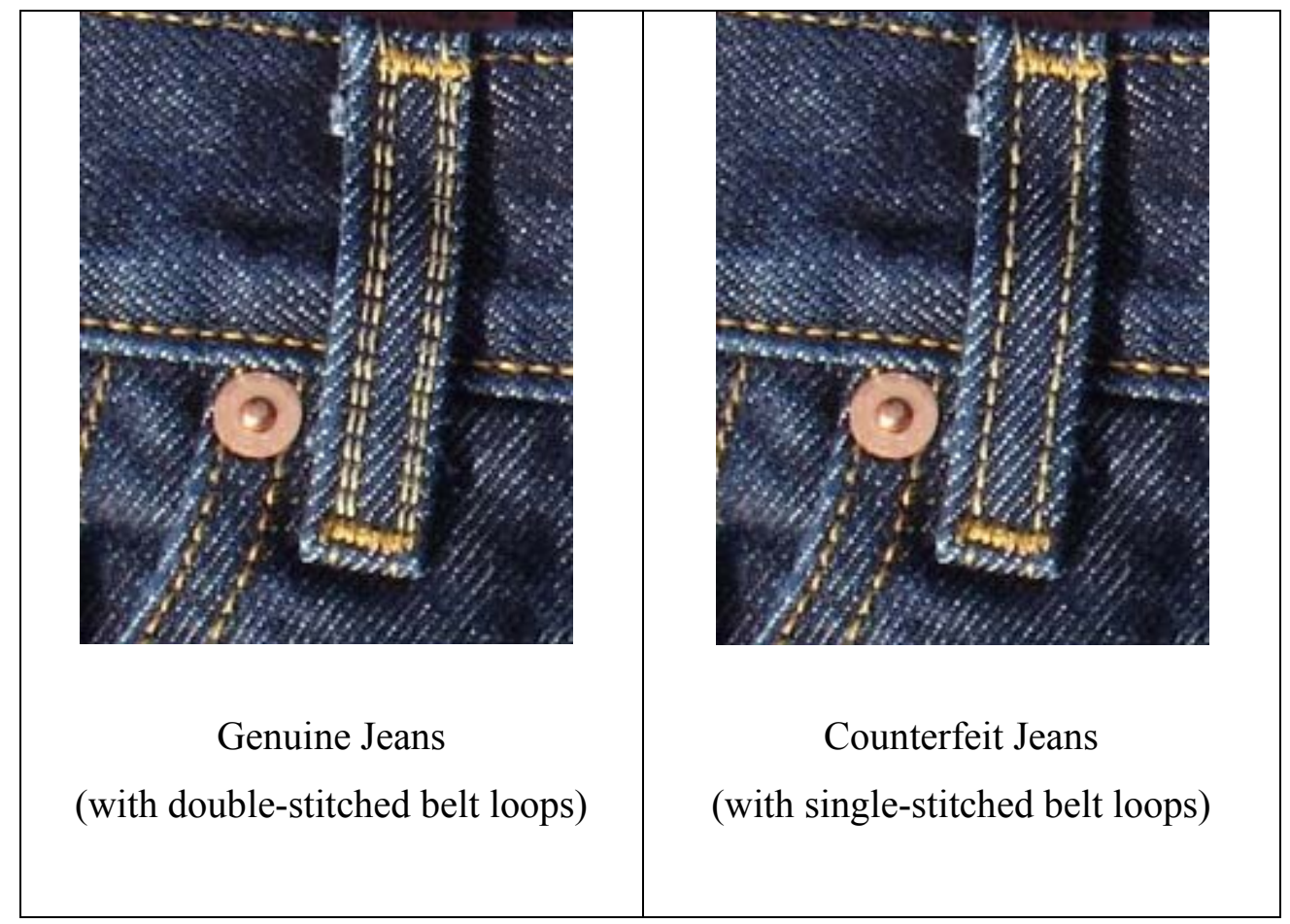


Table 1 - Standardised Regression Coefficients- Study 3

\begin{tabular}{|c|c|c|c|c|c|}
\hline $\begin{array}{l}\text { Independent Variable = } \\
\text { Outcome Severity (OS) }\end{array}$ & $\begin{array}{l}\text { OS } \\
(\mathrm{X})\end{array}$ & $\begin{array}{l}\text { Target } \\
\text { (MO) }\end{array}$ & $\begin{array}{c}\text { OS } \times \\
\text { Target } \\
(\mathrm{X} \times \mathrm{MO})\end{array}$ & $\begin{array}{c}\text { PA } \\
\text { (ME) }\end{array}$ & $\begin{array}{c}\text { PA } \times \\
\text { Target } \\
(\mathrm{ME} \times \mathrm{MO})\end{array}$ \\
\hline
\end{tabular}

\section{Mediation Model}

1 Probability Estimate (PE)

$.18^{*}$

2 Perceived Attention (PA)

$$
.21 *
$$

3 Probability Estimate (PE)

.13

\section{Mediated Moderation Model}

4 Probability Estimate (PE)

$\begin{array}{lll}-.03 & .15 \quad .30 * *\end{array}$

5 Perceived Attention (PA )

$.07 \quad .02 \quad .22 *$

6 Probability Estimate (PE)

$-.04 \quad .14 \quad .26 *$

$.19^{*}$

$-.01$

Note: $\mathrm{X}$ - Independent Variable, Y - Dependent Variable, ME - Mediator, MO - Moderator $* p<.05, * * p<.01$. 